\title{
Celibidache e o Fim da História da Regência
}

\author{
Luís Antônio Giron
}

\section{Introdução}

$\mathrm{O}$ século $\mathrm{XX}$ assistiu ao surgimento da arte da regência no fulcro da cultura de massa. Os maestros se tornaram divos do mesmo porte dos cantores e dos ícones do pop. Tudo porque eles se colocaram à frente do processo de reprodução e divulgação da música por meio dos discos e dos vídeos, assim como haviam assumido em definitivo a direção da orquestra no início do século XIX. A figura do regente tem o papel social amplificado. Leva ao grande público alguns dos arcanos de uma arte de pequenas multidões, surgida no final do século XVIII: o concerto sinfônico. Virou tradutor, prestidigitador, ator, líder de seita. Tudo graças menos à arte do que à técnica.

O maestro romeno Sergiu Celibidache, nascido em 1912 e falecido em 15 de agosto de 1996, em Paris, representa a mais eloqüente reação ao aprisionamento da música pelos meios de reprodução. Crítico virulento da contemporaneidade, ele procurou manter viva a idéia da música como momento único, tributária do romantismo. Afirmou-se como guru de um curioso zenbudismo germânico da regência. Religião, ainda que puramente estética e como substituta - assim intui o crítico George Steiner já em 1971 - é o papel destinado à música neste fim pós-utópico de século ${ }^{1}$. Steiner percebe o fenômeno contra o qual se insurge 
Celibidache: o da "musicalização" da cultura e do "afastamento da palavra".

O maestro era chamado de "o Kaspar Hauser romeno", o "último sumo-sacerdote da arte", a coruja que aterrissa no fim da história, no delírio romântico da destruição, derradeiro protesto contra uma suposta degeneração dos valores da cultura ocidental. Claro que sua luta se revela inútil, pois mesmo seus concertos mereceram centenas de gravações, hoje comercializadas por selos clandestinos. Só à frente da Orquestra Filarmônica de Munique, que dirigiu desde 1979, são 25 títulos. Celibidache ignorava-as como excrescências mercadológicas. Ele respondeu ao século XX com diatribes e uma arte de anacoreta, antitecnológica. Fundamentou o oficio do regente pelo avesso do ofício dos regentes contemporâneos. Recusou-se a reconhecer qualquer miasma de aperfeiçoamento na regência desde a morte de seu protetor, o maestro alemão Wilhelm Furtwängler, em 1954, aos 68 anos de idade.

Este ensaio, busca demonstrar como as teses do artista romeno ainda são capazes de produzir frisson, mesmo que impraticáveis em seu fundamento. Celibidache foi a capitulação ad absurdum da arte como objeto único e a realização completa desta arte, por meio de um método exemplar e a leitura crítica da árvore genealógica da regência. Ao pregar o avesso do cânone observado pelos músicos, e pelo mundo, Celibidache representou igualmente a impossibilidade da dissidência, da rejeição ao microfone $\mathrm{e}$ ao canhão de laser que tudo capturam e convertem em produto. Sua atitute artística retrucava à tecnologia e, de certa maneira, foi a mais afetada por ela do que qualquer outro maestro de sua geração. Dimensionar sua importância e descrever seus procedimentos básicos é o objetivo do presente texto.

Uma longa entrevista concedida por Celibidache em outubro de 1993 em São Paulo, pouco antes de um concerto que dirigiu com a Orquestra Filarmônica de Munique, que redundou em duas reportagens e uma crítica ${ }^{2}$, e a biografia Celibidache - Der Andere Maestro (Celibidache - O Outro Maestro), do jornalista Klaus Umbach, lançada em $1995^{3}$, formam as fontes essenciais deste 
trabalho. Além disso, George Steiner em No Castelo do Barba Azul, Giorgio Graziosi no volume de ensaios L'Interpretazione Musicale $^{4}$, Edward Said em Elaborações Musicais ${ }^{5}$ e Elias Canetti no texto fundamental Massa e Poder ${ }^{6}$ contribuem para formar o leitmotiv teórico que rege a idéia do anoitecer da cultura erudita aqui desenvolvida.

\section{Alteração do gesto}

Ao inverso do que axiomatizava Celibidache, a arte experimentou neste século, especialmente no pós-guerra, uma melhora no sentido formal. As grandes escolas de regência surgidas no século XIX geraram frutos e hoje são poucos os regentes que se podem dar ao luxo de viver de um saber limitado, ou apartados de um tronco estético. A excelência e a superexposição fazem suas exigências. $O$ regente finimilenar se vê diante de desafios nunca enfrentados antes, como o da melhor forma de lidar com a tecnologia, a recepção da massa e as epidemias da moda.

A tecnologia transformou o gesto de comando do chefe de orquestra em objeto registrável e segmentável. A imagem captura a gestualidade do maestro, antes tida como inacessível, e apenas dirigida aos músicos. Graças à tecnologia, o maestro se investe de um aspecto frontal e passa a ser o bailarino da orquestra. $\mathrm{O}$ que antes era didascália (indicação precisa), ou mero ornamento, passa a ser no século presente uma coreografia transcendental. A orquestra existe para ir dar na ponta dos dedos ou da batuta do maestro. O grupo de músicos no palco se torna a imagem espelhada da platéia, um e outra hipnotizados, narcotizados pelo poder de domesticação do regente. Detentor das prerrogativas conquistadas pela arte, ele fornece sentido ao momento da execução e usufrui do privilégio de se perpetuar na imagem reproduzível. Simultaneamente ele exercita o momento intransferível do espetáculo e seu palpável simulacro. A imagem em movimento nasce no ano do aparecimento da psicanálise, 1895. Na música, é a data em que o compositor alemão Richard Strauss (1864-1949) se afirma como 
maestro, regendo seu poema sinfônico Till Eulenspiegel em Munique. Por sinal, Strauss, discípulo do ambivalente Hans von Bülow (a um tempo wagneriano e antiwagneriano), formaria o professor Heinz Tiessen (1887-1971), com quem Celibidache estudou ao chegar a Berlim, em 1936, para aprender regência, metafísica e matemática.

A gestualidade teatral de Strauss, e a ressonância desta sobre a do jovem Celibidache, certamente inspirou o pensador búlgaro Elias Canetti em Massa e Poder, livro publicado em 1960, que estabelece uma taxionomia informal do comportamento das turbas e seus timoneiros no contexto dos conflitos mundiais. No penúltimo capítulo, "Aspectos do Poder", Canetti disseca a função do regente na cultura européia pré-revolução tecnológica. "Inexiste expressão mais manifesta do poder do que a atividade do maestro", diz; "Cada detalhe de seu comportamento público é característico; o que quer que ele faça lança alguma luz sobre a natureza do poder. Alguém que nada soubesse a seu respeito poderia deduzir uma a uma as características do poder a partir da contemplação atenta do regente"7. Segundo Canetti, o regente se considera o servidor-mor da música, embora possua o dom de controlar as vozes da orquestra (metáfora da vária humanidade) e "um líder para a multidão presente na sala": "O público tem sempre suas costas diante de si, como se ele fosse sua meta. Se ele se virasse uma única vez, o encanto estaria quebrado. O caminho que o público percorre não seria mais um caminho, e decepcionadas, as pessoas ver-se-iam sentadas numa sala imóvel. Contudo, elas podem ter certeza de que ele não vai se voltar. E isso porque, enquanto elas o seguem, o regente tem à sua frente um pequeno exército de músicos profissionais a dominar. Também aí a mão o auxilia. Não, porém, indicando apenas os passos seguintes - como faz para as pessoas na platéia -, mas transmitindo ordens".

Em resumo, o regente é "a soma viva das leis", aquele que "atua sobre ambos os lados do mundo moral". Canetti atribui-lhe um estatuto de Leviatã: "Pelo mandamento de suas mãos, indica o que vai acontecer e impede que aconteça o que não deve aconte- 
cer. Seu ouvido perscruta o ar à procura do proibido. Assim, para a orquestra, o regente representa de fato a totalidade na obra, tanto em sua simultaneidade quanto em seu desenrolar, e, considerando-se que ao longo da execução o mundo não deve consistir senão na obra, durante esse tempo ele é o soberano do mundo".?

Celibidache calhava perfeitamente à descrição. Ele sentia a nostalgia do poder perdido, do logocentrismo, da aura hoje convertida em repetição. Com a assunção da imagem técnica, o regente já não está mais de costas, mas diante do público, exposto em 360 graus, sob todos os ângulos possíveis. O quadro de Canetti está, portanto, datado, embora a questão do poder ali expresso ainda tenha validade. $\mathrm{O}$ guia agora cede lugar ao mágico, dotado de gesticulações transcendentais, e um poder oculto, de organizador, de gerenciador do processo de produção musical. Como analisa Edward Said, o intérprete atual ganha neste século ares de ser olímpico, inatingível ${ }^{10}$. Para o estudioso norte-americano de origem palestina, o pianista canadense Glenn Gould é a figura prototípica do artista que troca a arena sangrenta da sala de concertos pelo estúdio de gravação e faz disso uma profissão de fé na técnica. Celibidache impunha-se pela atitude contrária: adotava a arena da performance pública contra o estúdio e o eterno retorno de uma determinada interpretação.

A massa absorve a figura do regente e do virtuose como a de um campeão insuperável. A platéia, hoje constituída pela malta oculta de espectadores de CDs, não pode mais querer segui-lo e sim apenas reverenciá-lo como vencedor de uma competição no ranking dos virtuoses. "De muitas maneiras, o toca-discos moderno transforma a sala de estar em uma sala de concertos ideal", comenta George Steiner". "Ela permite um novo melindre da audição: nada de perturbações causadas pelas tosses alheias, nada de barulho de pés, nada de notas desafinadas. Os discos de longa duração alteraram as relações entre o ouvido e o tempo musical, visto que podem ser postas para tocar de uma só vez, de modo ininterrupto, ou com um intervalo mínimo, obras longas - uma sinfonia de Mahler - ou sequências interligadas como as Variações 
Goldberg agora podem ser ouvidas integralmente, em casa, e também repetidas ou segmentadas à vontade". Steiner explica que a interação entre notação de tempo musical e fluxo de tempo real do ouvinte é um fato arbitrário, mas revelador. Vê como fato inédito na história o de toda música poder ser ouvida "a qualquer hora $\mathrm{e}$ como som ambiente doméstico"'2. "Fita, rádio, toca-discos emitem uma torrente infindável de música, em qualquer momento ou circunstância do dia".

Celibidache adotava a torrente infindável da flutuação agógica (o "espichamento" ad nauseam dos tempos, ao sabor da expressividade do momento) contra a torrente tecnológica e das modas. Sabia que a batalha já estava perdida. O tempo do triunfo do Leviatã-maestro escoa, enquanto o registro burocrático do regente-mágico permanece. Se atualmente o maestro que se vira não decepciona a turba, Celibidache evitava encarar o público. Quando o fazia, era para ostentar o olhar de górgona, petrificador.

\section{A carreira do Leviatã}

"Dirigir é uma possibilidade, um acaso a ser liberado"13. Esta frase de Celibidache serve para encimar sua trajetória. Há quem diga que um dado contingente definiu seu modo de agir: o fato de haver perdido para Herbert von Karajan o direito à sucessão de Furtwängler à batuta da Orquestra Filarmônica de Berlim. Isso teria precipitado o rancor, revelado a língua ferina do preterido e, por oposição ao discomaníaco Karajan, definido seu método de trabalho avesso à tecnologia. O conhecimento de sua carreira demonstra, porém, que a coerência o conduz à dissenção natural com Karajan. Quando o maestro austríaco assumiu Berlim, venceu uma maneira contemporânea de tratar o produto musical. A indignação do perdedor, portanto, foi legítima.

Celibidache chegou à música por interesse filosófico. "Queria saber o sentido daquela linguagem sem palavras, matemática e poética ao mesmo tempo"14. Estudou na Universidade de Berlim a partir de 1936. Dedicou-se a reger corais, passou por dificuldades, 
estudou matemática e zen-budismo. Atuou pela primeira vez à frente da Filmônica de Berlim em agosto de 1945. No ano seguinte, assumiu a batuta da orquestra, a convite do exército russo de ocupação. Começou a trabalhar com Furtwängler, de retorno do exílio suíço.

Discípulo da linha wagneriana de regência, o maestro romeno se destacou pela gesticulação espetacular, a flutuação agógica e o excesso de ensaios. Numa reportagem fotográfica feita em Londres quando de sua estréia internacional, em 1948, o regente aparece com a cabeleira desgrenhada, a fazer as expressões mais contorcidas, os sorrisos mais abertos, as mãos crispadas. Especialista em Bruckner, sua versão da oitava sinfonia do mestre de Linz já durava, na época, cerca de 106 minutos. Para se ter uma idéia, a mesma obra regida por Karajan com a Orquestra Filarmônica de Berlim durava 81 minutos, enquanto que Carl Schuricht e a Filarmônica de Viena levam apenas 71 minutos. Sua flutuação se aproximava do slow motion.

"A orquestra deve chegar ao ponto onde o maestro está. Faço muitos ensaios para poder passar a técnica e a interpretação. Para um crítico conhecer uma orquestra, tem que ouvir os ensaios", declarou, em bom espanhol, quando esteve no Brasil, em $1993^{15}$.

Depois de uma carreira de turnês internacionais, foi o escolhido por Furtwängler para sucedê-lo. Mas este morreu no início de dezembro de 1954, poucos dias depois daquele que seria o derradeiro concerto de Celibidache com a Filarmônica de Berlim. Karajan assumiu-a em 13 de dezembro. Celibidache só voltaria a regê-la em 31 de março de 1992, em comemoração aos seus 80 anos, e isso por insistência do presidente alemão, Richard von Weizsäcker. Nesse meio tempo, deram-se os fatos principais de sua vida. Dirigiu a Orquestra Kapelle Copenhague de 1960 a 1964. De 63 a 71, foi condutor da Orquestra Sinfônica da Rádio Sueca. Voltou para a Alemanha em 1972, a fim de dirigir, em Stuttgart, a Sinfônica da Rádio do Sul da Alemanha. Ali ficou até 1977. Dois anos depois, assumiu a Filarmônica de Munique, para ali permanecer. Já não regia de pé, mas suas convicções permaneciam intactas: nada de 
ópera nem gravações, apesar de ter concedido fazer videolasers a partir de 1990, mediante súplica especial da direção da Filarmônica de Munique, por sua vez pressionada pelo governo alemão a fim de que obtivesse receita própria. "Ópera é falsa, a filha bastarda das artes", disse a seu biógrafo ${ }^{16}$. Declarou no Brasil: "Não se vende música. Estamos vendendo o velhinho de cabelos brancos, a performance deste ou daquele instrumentos. Vendemos o espetáculo. Não o músico. Serve para que ganhemos um pouco mais de dinheiro. O pessoal da Filarmônica de Berlim tem dinheiro, casa de campo etc. porque vende discos. Isso não nos interessa" ${ }^{\prime 1}$. Até o fim da sua vida, continuava tratando o microfone com desconfiança: "O microfone não deixa de ser uma massa metálica. Capta apenas 30 por cento do som original. Rebaixa a música. Nos estúdios tudo é perfeito demais. Ao vivo, não"18.

\section{Filosofia da regência}

Em entrevistas ao longo de sua carreira, Celibidache citou pejorativamente astros famosos e criou animosidades. Mas a violenta ironia do maestro encerrava uma visão crítica sobre o fenômeno da regência e uma filosofia de conduzir orquestras - ou, para parodiar um conterrâneo seu, o filósofo Cioran, criou um breviário de sombras da batuta.

Não via com bons olhos o aplauso vazio do público e ironizava o papel dos seus colegas. "Aplauso quase sempre perturba. Quando eu toco bem e o público demonstra que entendeu, então eu me sinto feliz. Mas geralmente é uma demonstração vazia, muito vazia, de aprovação. Não a recebo bem". Para ele, regentes eram "pessoas primitivas e sem cultura"19. "Um maestro não precisa ser um músico, mas pode ser que seja. Um homem cuja função é pôr a orquestra em ordem e juntar os instrumentos, que pouco barulho faz e efetivamente produz quase nenhuma música audível, não pode ser chamado de músico. Primeiro vem a organização, depois a música"20.

A missão do diretor de orquestra, segundo ele, era ser o "fiel testamenteiro do compositor"21. Como testamenteiro, porém, 
Celibidache lia o passado com irreverência, sobretudo suas maiores influências. Berlioz, para ele, é "mestre do desvio": "Foi um revolucionário na instrumentação. Mas lhe faltava conhecimento suficente em harmonia. Não harmonizava nem mesmo um coral corretamente. Posso citar centenas de linhas de baixo e modulações erradas nele"22. Wagner preferiu a obra-de-arte-total a desenvolver seus dotes: "Ele tinha anseios pequenos-burgueses de se tornar escritor e pensador. Isso era o principal para ele. Não se deu conta de que era um grande músico. Dirigiu todo seu esforço para a obra-de-arte-total, e isso não era outra coisa que o sonho de um pequeno burguês" ${ }^{\prime 23}$. O maestro reconhecia o valor de Tchaikovsky: "É um poderoso sinfonista e um ilustre desconhecido na Alemanha" ${ }^{\prime 24}$, homem de profundidades só reconhecidas na Rússia natal. Stravinsky, segundo nosso viellard terrible, é "um diletante genial", um mestre "sem estilo, de tanto explorar estilos alheios"25.

E Schoenberg? "Um compositor de horrorosa burrice. Tudo nele soa igual. Felizmente sua influência durou pouco, seu sistema dodecafônico, com todos os imitadores e apóstolos, era tão mesquinho e desconjuntado quando o sistema comunista" ${ }^{26}$.

Para os colegas tampouco esbanjava elogios. Lorin Maazel, "uma criança de dois anos que fala de Kant"27. Karajan, "um nazista que fez duas vezes a ficha no partido nazista para trabalhar"28. Hans Knnappertsbuch: "Esse não sabia nada de nada. O público o aplaudia, não importava o que regesse ou os erros que cometia. Gostava de colocar uma melodia uma oitava abaixo só para se divertir. Ninguém notava" ${ }^{29}$. Solti, "um pianista que não sabe dirigir orquestra"30. Não poupava nem mesmo Toscanini, o artista que consolidou a fidelidade como procedimento mais legítimo da regência. "Dizem que Toscanini era o único a respeitar o que estava na partitura. $\mathrm{Na}$ época, Toscanini era o único que não fazia música, apenas produzia notas. Foi uma fábrica de fazer notas"31. E aqui a expressão Notenfabrik tem em alemão, como em português, o sentido musical e monetário...

A maledicência se reveste de um sentido catártico para essa coruja da história. Libertando-se das influências e de quem influen- 
ciou, Celibidache parecia querer construir uma nova doutrina, como se isso fosse possível no instante de queda dos sistemas.

Seu padrão de regência nada tinha de metafísico: ensaios incessantes, técnica alemã, controle sobre a partitura e os músicos. O repertório veio da mainstream da música sinfônica européia: Beethoven, Bruckner, Mozart, Mahler, Schubert, Richard Strauss. Dava as costas ao público para hipnotizá-lo. Às vezes regia senza batuta, embora esta tivesse uma função clara: "A batuta imprime sutileza ao movimento ao braços, tirando deste o peso habitual. Ela carrega uma rigidez necessária." 32 . As duas mãos possuem o mesmo peso, e podem trocar de função, ora uma expressiva, ora outra marcando o tempo. Em algumas ocasiões a esquerda toma a batuta, para assim romper com.a rotina. "Ditador, eu? Um tirano? Não, nunca. Mozart é o ditador, ele dá as ordens através de sua obra"33. Curiosamente, a fidelidade de Celibidache não rezava pelos cânones fixos de interpretação típicos da prática atual.

De certa forma, ele buscava fora do pentagrama a fórmula para o seu método. Discípulo do gnóstico indiano Sai Baba, é na doutrina zen e no vocabulário da levitação que o músico encontrou o motor de inspiração. Agia como um genuíno guru. Seus alunos eram discípulos; deviam observar uma disciplina peripatética, seguindo-o por onde for. Dizia que se cansou de encontrar estudantes que se interessavam menos pela essência da música do que pela carreira, e reduziu o número de alunos. Tentava orientar por parábolas de místico tardio. Ensinava coisas como: "Tão logo a pena toca o papel, o sentido foge. É impossível captar o sentido das coisas pela palavra"34. Ou, sobre música: "Quando o camponês canta de manhã, está fazendo música pura. Ele não se preocupa com nada, nem com o texto nem com as notas. Preocupa-se com a beleza da manhã que ele celebra. Eis a grande profundidade da arte. Esta transcende os valores. Como se dá esse fenômeno, não sei dizer. O que aconteceu depois do concerto? Nada. O que é necessário esclarecer? Nada. Alguém pode me dar uma explicação suficiente da água?"35. Música é um fenômeno indefinível. "Tente falar sobre música com Bernstein, um homem inteligente. Ele não 
tem nenhuma idéia sobre o assunto"36. Ela se dá no instante da performance: "O que será esta noite não sei. Não sei se será música. Uma sinfonia de Beethoven não existe mais Ela ainda vai ser feita. Hábitos não devem predominar na arte dos sons" ${ }^{\prime 37}$.

\section{Eternidade técnica}

Celibidache elaborou um corpo doutrinal baseado na indeterminação, no leito incessante do tempo. A importância do maestro no ambiente pós-cultural está na percepção da decadência dos valores estéticos tradicionais e na tentativa desesperada de salvar alguns desses valores para a posteridade. "Infelizmente o futuro da regência está no passado", desferiu o guru, sorrindo da própria ironia ${ }^{38}$. No mundo técnico, o papel do maestro talvez seja o de desautomatizador dos procedimentos consuetudinários das orquestras e das platéias. Isso não acontece. Celibidache, contudo, insistia em perscrutar o proibido, em apontar o assassinato da música por seu símile sonoro.

Segundo esse filósofo de fragmentos, o drama de seu antecessor, Furtwängler, foi ter tentado se eternizar no long playing e o resultado ter sido caricatural. O drama de Celibidache foi o de ter percebido que os meios técnicos prendem, eternizam, convertem sua arte em objeto de manipulação. Nos videolasers em que concedeu aparecer, pode-se recuar ou avançar, ou congelar a imagem de Celibidache num ponto em que os braços levantados exageradamente atingem o ápice de uma sinfonia. A metafisica cede espaço à imanência, o gesto está vivo, mas congelado, como uma caricatura. Ainda que registrado, catalogado e afetado pela tecnologia, o maestro jamais dará a batuta a torcer. Crê na partícula mínima, indecomponível e incaptável, da música: no fato de ela fluir e ter o direito de se encerrar. No cair da noite da cultura erudita, os dois lados do mundo moral, público e artistas, perderam a sensibilidade para a finitude. Sentados, esperam que a batuta jamais se suspenda.

Para Celibidache, a música ainda não começara. 


\section{NOTAS}

1. STEINER, George (1971). No castelo do Barba Azul (algumas notas para a redefinição da cultura). São Paulo, Companhia das Letras, 1991. $154 \mathrm{p}$.

2. GIRON, Luís Antônio (1993). Maestro critica Karajan e a tecnologia. In: Folha de S. Paulo, 5 de outubro de 1993, p.1-8. . Celibidache começa hoje turnê brasileira. In: Folha de S. Paulo, 5 de outubro de 1993, Ilustrada, p. 4-5. Sergiu Celibidache e Filarmônica de Munique resgatam o instante. In: Folha de S. Paulo, 6 de outubro de 1993, ilustrada, p. 4-5.

3. UMBACH, Klaus (1995). Celibidache - der andere maestro (biographishce reportagen). München, Piper, 1995. $336 \mathrm{pp}$.

4. GRAZIOSI, Giorgio (1957). L'Interpretazione musicale. 4." ed.,Torino, Einaudi, 1967.

5. SAID, Edward (1991). Elaborações musicais. Rio, Imago, 1992. 220 pp.

6. CANETTI, Elias (1960). Massa e Poder. São Paulo, Companhia das Letras, $1992.487 \mathrm{pp}$.

7. Idem nota 6, p. 395 .

8. Idem p. 396-397.

9. Idem, p. 397.

10. Idem nota 5, p. 30 .

11. Idem nota 1, p. 129-130.

12. Idem, p. 128.

13. Idem nota 3 , p. 33 .

14. Idem nota 2.

15. Idem ibidem.

16. Idem, p. 22.

17. Idem nota 2.

18. Idem ibidem.

19. Idem nota 3, p. 47.

20. Idem, p. 30.

21. Idem, p. 34.

22. Idem, p. 23.

23. Idem ibidem.

24. Idem ibidem.

25. Idem ibidem.

26. Idem nota 3, p. 24.

27. Idem, p. 190.

28. Idem nota 2.

29. Idem ibidem. 
30. Idem ibidem.

31. Idem nota 3, p. 190.

32. Idem, p. 31 .

33. Idem, p. 30.

34. Idem nota 2 .

35 . Idem nota 3, p. 34 .

36. Idem ibidem.

37. Idem nota 2.

38. Idem ibidem.

Luís Antonio Giron é jornalista, crítico musical e mestrando em musicologia junto ao Departamento de Música da ECA-USP. 